\title{
A NEW COMPENSATION METHOD FOR IMPROVING STATIC CHARACTERISTICS OF A PROPORTIONAL POPPET VALVE
}

\author{
Wu Pingdong*, Hitoshi Maekawa, Kazushi Sanada** \\ Ato Kitagawa**, Toshio Takenaka*** \\ *Dept. of Control Engineering \\ Beijing Institute of Technology \\ Beijing, China \\ ${ }^{* *}$ Dept. of Control Engineering, Faculty of Engineering \\ Tokyo Institute of Technology \\ Tokyo, Japan \\ ***Dept. of Mechanical Engineering, Faculty of Engineering \\ Musashi Institute of Technology \\ Tokyo, Japan
}

\section{ABSTRACT}

A proportional poppet valve is a new oil-hydraulic valve whose main poppet lift is linearly controlled by a pilot valve. Like a usual and simple oil-hydraulic valve, the total flow rate of this new poppet valve is influenced by load pressure. The present paper describes a new compensation method to decrease the influence of load pressure, and this new method is named as area compensation method. The area compensation method is based on the design of top and bottom areas of the main poppet. From detailed experiments and analysis, this new compensation method has been found to be effective and practical. The structure of the proportional poppet valve designed by this area compensation method is simple. The analysis of static characteristics is easily and accurately performed.

\section{KEYWORDS}

Oil-hydraulic Control Valve, Proportional Poppet Valve, Static Characteristics, Compensation Method

\section{NOMENCLATURE}

$A_{c}:$ top area of main poppet

$A_{r}$ : bottom area of main poppet on which load pressure acts

$A_{s}$ : bottom area of main poppet on which supply pressure acts

$c_{c}$ : discharge coefficient of control orifice

$c_{m}$ : discharge coefficient of main valve $c_{y}$ : discharge coefficient of pilot valve

$D$ : poppet diameter

$f_{y}$ : opening area of pilot valve

$p_{c}$ : control pressure

$p_{r}$ : load pressure

$p_{s}$ : supply pressure

$q_{c}:$ flow rate through control orifices

$q_{m}$ : flow rate through main poppet valve

$q_{\text {, }}$ flow rate through load valve

$q_{y}:$ flow rate through pilot valve

$S_{r}, S_{s}$ : area ratios

$W_{c}$ : width of control orifices

$W_{m}$ : coefficient of opening area of main poppet valve

$x$ : lift of main poppet

$x_{i}$ : underlap of control orifices

$\rho$ : oil density

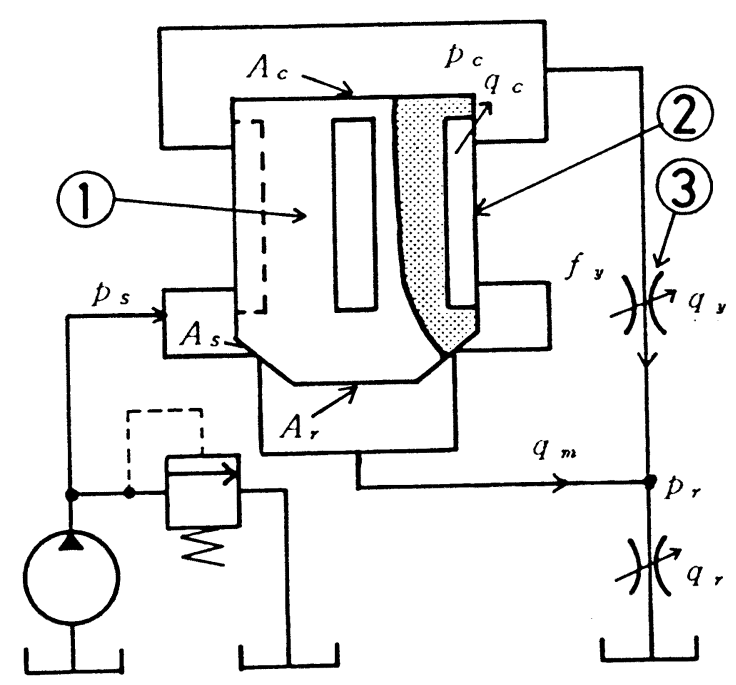

Fig. 1 Schematic diagram of a proportional. poppet valve 


\section{INTRODUCTION}

A proportional poppet valve is a new oil-hydraulic valve whose main poppet lift can be linearly controlled by a pilot valve. A schematic diagram of the proportional poppet valve is presented in Fig.1. This valve is mainly constructed with a poppet valve (1), control orifices (2.) and a pilot valve (3). Control orifices are the grooves on the side surface of the main poppet. During steady state condition, the main poppet lift can be linearly controlled by the pilot valve, since oil flow rate through control orifices equals oil flow rate through the pilot valve. This new type of valve was proposed by B.Andersson(1), and was named as proportional poppet valve. The fundamental static and dynamic characteristics of this proportional poppet valve have been investigated by the authors (2) $\sim(4)$.

Like a usual and simple oil-hydraulic valve, the total flow rate of this new poppet valve is influenced by load pressure. The present paper describes a new compensation method to decrease the influence of load pressure on the total flow rate of the proportional poppet valve. This compensation method was proposed by one of the authors, P.WU, and was named as area compensation method. The area compensation method is based on the design of top and bottom areas of the main poppet to compensate the influence of load pressure. The structure of the valve designed by this area compensation method is very simple. The analysis of static characteristics can be easily and accurately performed.

\section{EXPERIMENTAL CIRCUIT}

An experimental oil-hydraulic circuit is presented in Fig.2. Experiments were conducted to test static characteristics of the proportional poppet valve (1) which was used as a flow control valve. $0 i 1$ flow was generated by a piston pump (8) and the flow pressure was limitted by a relief valve (9). The pressure setting of the relief valve was $5 \mathrm{MPa}$ during experiments. Flow rate was controlled by the proportional poppet valve (1). Pressure at the outlet of the poppet valve (1) was measured by a pressure gauge (4). Oil flow from the poppet valve (1) was made to pass through the throttle valve (ID which was used as a load valve. The flow rate through the throttle valve (ID) was measured by a flow meter (10). In this experiment, two kinds of pilot valves were used. One was a simple throttle valve (3) and another was a pressure-compensated flow control valve (2). Selection of these two pilot valves was made possible by a directional control valve (5). For measuring oil flow rate through the pilot valve, another directional control valve (7) was operated and the pilot oil flow was led to a flow meter (6).

\section{FUNDAMENTAL STATIC CHARACTERISTICS}

Static Characteristics of an Uncompensated Valve

In this section, fundamental static characteristics of an uncompensated proportional poppet valve are briefly described(2). Referring to Fig.1, following equations are easily obtained.

- Flow rate through main poppet valve

$$
q_{m}=c_{m} W_{m} \times \underset{V}{2} \rho\left(p_{s}-p_{v}\right)
$$

- Flow rate through pilot valve ( a simple throttle valve)

$$
q_{y}=c_{y} f_{y} / \frac{2}{\rho}\left(p_{c}-p_{r}\right)
$$

- Flow rate through control orifices

$$
q_{c}=c_{c} W_{c}\left(x+x_{i}\right) \sqrt{\rho} \rho_{\rho}^{2}\left(p_{s}-p_{c}\right)
$$

Continuity equations on steady state condition are written as

$$
\begin{aligned}
& q_{y}=q_{c}, \\
& q_{r}=q_{m}+q_{y} .
\end{aligned}
$$

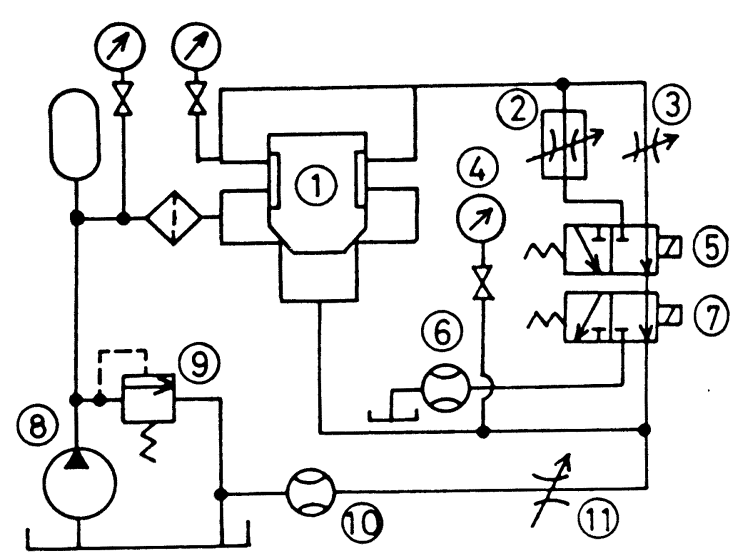

Fig. 2 Experimental circuit 
On steady state condition, three forces caused by pressures ( supply pressure, load pressure and control pressure) and a steady state flow force act on the main poppet valve. Comparing with other three forces, the steady state flow force is small enough to be omitted. In the case of the proportional poppet valve used in experiments, the steady state flow force was only about $3 \%$ of total force. Therefore in this analysis, steady state flow force was omitted. For the forces acting on the main poppet to be in equilibrium, the following relation among supply pressure $p_{s}$, load pressure $p_{r}$ and control pressure $p_{c}$ is necessary;

$$
p_{c}=S_{s} p_{s}+S_{r} p_{r}
$$

where

$$
S_{s}=\frac{A_{s}}{A_{c}} \text { and } S_{r}=\frac{A_{r}}{A_{c}} \text {. }
$$

From Eq. (2) $\sim$ Eq. (4) and Eq. (6), the main poppet lift $x$ is given by

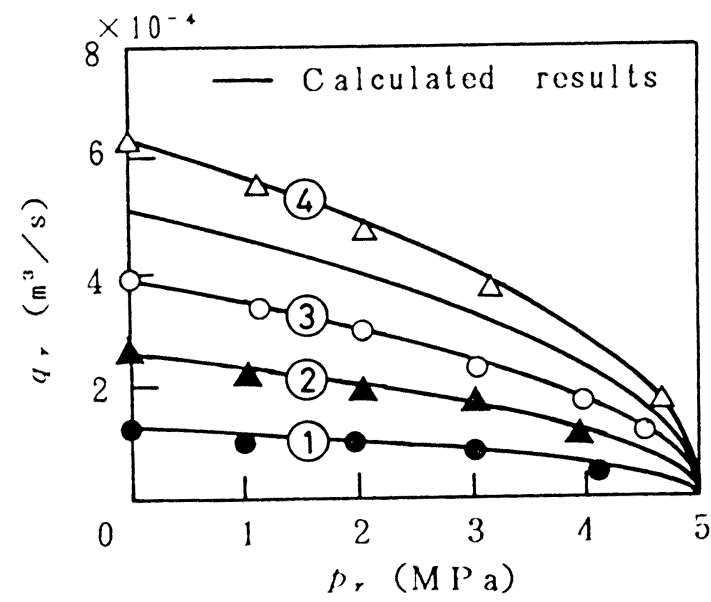

Fig. 3 Static characteristics of an uncompensated proportional poppet valve

Table 1 Symbols and pilot valve opening area $f_{y}$ in Fig.3, Fig. 7 and Fig. 8

\begin{tabular}{|l|l|l|}
\hline \multicolumn{2}{|c|}{} & $f_{y}\left(\mathrm{~mm}^{2}\right)$ \\
\hline (1) & $\bullet$ & 0.12 \\
\hline (2) & $\Delta$ & 0.24 \\
\hline$(3)$ & 0 & 0.18 \\
\hline (4) & $\Delta$ & 0.60 \\
\hline
\end{tabular}

$$
x=\frac{c_{y}}{c_{c} W_{c}} \sqrt{\frac{S_{s} p_{s}+\left(S_{r}-1\right) p_{r}}{\left(1-S_{s}\right) p_{s}-S_{r} p_{r}}} \cdot f_{y}-x_{i} .
$$

For a usual poppet valve, the following relation exists between area ratios;

$$
S_{s}+S_{r}=1
$$

Combining Eq. (8) and Eq. (9),

$$
x=\frac{c_{y}}{c_{c} W_{c}} \sqrt{\frac{S_{s}}{S_{r}}} \cdot f_{y}-x_{i} .
$$

From Eq. (1), Eq. (3) Eq. (6) and Eq. (9), the total flow rate is given by

$$
\begin{aligned}
& q_{r}=c_{m} W_{m} \times \sqrt{\sqrt{\frac{2}{\rho}\left(p_{s}-p_{r}\right)}} \\
& +c_{c} W_{c}\left(x+x_{i}\right) \sqrt{\frac{2}{\rho} S_{r}\left(p_{s}-p_{r}\right)} .
\end{aligned}
$$

From Eq. (10) and Eq. (11), it becomes clear that the lift $x$ and the total oil flow rate $q$, can be linearly controlled by the pilot valve opening $f_{y}$. It is also obvious that the total flow rate $q_{r}$ is considerably influenced by load pressure $p_{r}$. Experimental results of relations between $q_{r}$ and $p$, for various pilot valve opening areas $f_{y}$ are presented in Fig.3. Symbols in Fig. 3 are explained in Table 1. As load pressure $p$, increases, total flow rate $q$, decreases. When load pressure $p_{\text {r }}$ equals supply pressure $p_{s}(=5 \mathrm{MPa})$, the total flow rate $q$, becomes zero. From these experimental results, it becomes clear that the total flow rate of an uncompensated proportional poppet valve is considerably influenced by load pressure.

Compensation Method by a Pressurecompensated Flow Control Valve

It is evident from considerations of the above section that an uncompensated proportional poppet valve is not suitable for a flow control valve, since the total flow rate is considerably influenced by load pressure. Usually, in order to improve static characteristics, a pressurecompensated flow control valve is used as a pilot valve(5). In this case, the pilot flow rate $q_{y}$ is not influenced by load pressure $p_{r}$ or control pressure $p_{c}$. The main poppet lift $x$ is given by

$$
x=\frac{1}{c_{c} W_{c}} \sqrt{\frac{\rho}{2 S_{r}\left(p_{s}-p_{r}\right)}} \cdot q_{y}-x_{i},
$$


and the total flow rate $q_{r}$ is given by

$$
q_{r}=c_{m} W_{m} x \sqrt{\frac{2}{\rho}\left(p_{s}-p_{r}\right)}+q_{y} .
$$

As is evident from Eq. (12), the lift $x$ linearly varies with the pilot flow rate $q_{y}$. When the load pressure $p_{r}$ increases, the lift $x$ increases. An increment in the poppet lift compensates the decrement in flow rate caused by load pressure. The experimental results of static characteristics of the proportional poppet valve with a pressure-compensated flow control valve are presented in Fig.4. In Fig.4, plots represent experimental results for three flow-rate settings of the pilot valve. Comparing with results of an uncompensated valve presented in Fig.3, static characteristics presented in Fig. 4 are more favorable. However, the use of a pressure-compensated flow control valve may cause problems, in that the valve structure becomes complicated and that the analysis of static characteristics is very difficult.

\section{NEW COMPENSATION METHOD}

In this chapter, a new compensation method to improve static characteristics of a proportional poppet valve is described. The new method is named as area compensation method. The area compensation method is the design method of area ratios to improve static characteristics of a proportional poppet valve. And in this method, instead of using a pressure-compensated flow control valve, a simple throttle valve is used as a

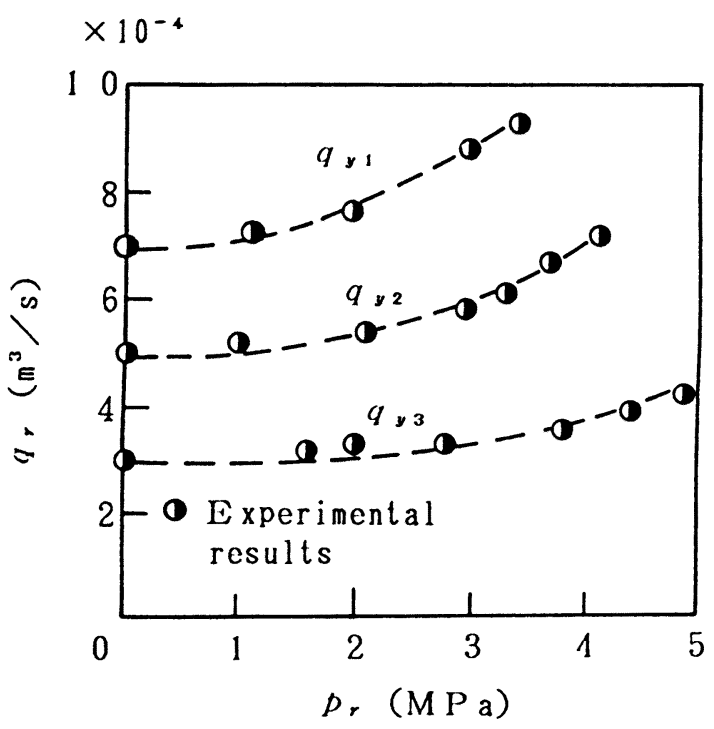

Fig. 4 Static characteristics of a proportional poppet valve with a pressure-compensated flow control pilot valve pilot valve. In this case, the relation between the main poppet lift $x$ and the pilot valve opening $f$, is given by Eq. (8). In the above chapter, it was assumed that sum of area ratios $S_{r}$ and $S_{s}$ equals unity. In area compensation method, the sum of these area ratios is greater than unity, i.e.,

$$
S_{s}+S_{r}>1
$$

Eq. (14) means that the sun of bottom areas $A_{s}$ and $A_{r}$ is greater than the top area $A_{c}$. As an example, the structure of such a proportional poppet valve is presented in Fig.5. A rod of small diameter is attached at the top of main poppet on which the control pressure $p_{c}$ acts, thereby making the area $A_{c}$ smaller than sum of areas $A_{s}$ and $A_{r}$.

Total flow rate of a valve compensated by the area compensation method is obtained from Eq. (1), and Eq. (3) Eq. (6) ;

$$
\begin{aligned}
q_{r}= & c_{m} W_{m} \times \sqrt{\frac{2}{\rho}\left(p_{s}-p_{r}\right)+c_{c} W_{c}\left(x+x_{i}\right)} \\
& \times \sqrt{\frac{2}{\rho} !\left(1-S_{s}\right) p_{s}-S_{r} p_{r}}
\end{aligned}
$$

Poppet lift $x$ is given by Eq. (8). Using Eq. (8) and Eq. (15), static characteristics can be calculated. In Fig.6, calculated results for a proportional

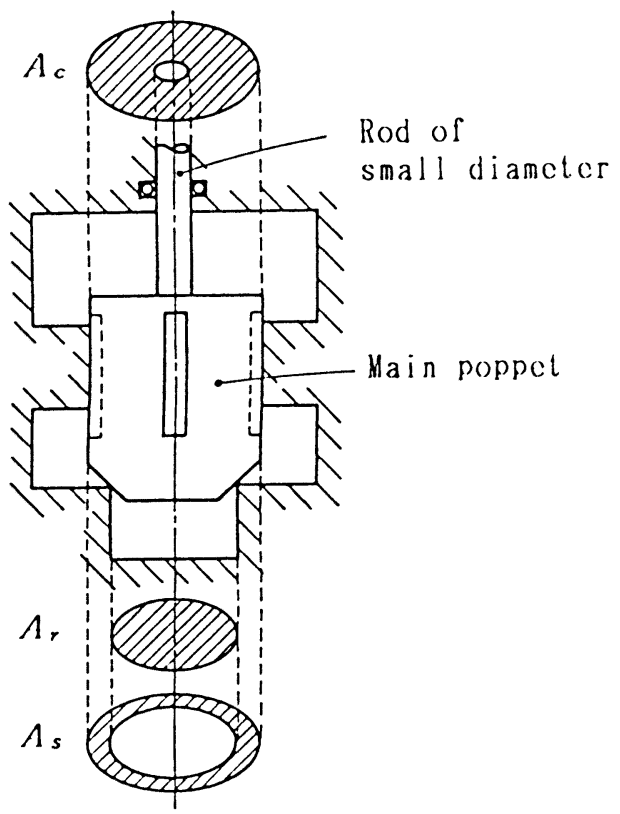

Fig. 5 Proportional poppet valve with a rod of small diameter 
poppet valve whose area ratios $S_{r}$ and $S_{S}$ equal $0.50,0.55$ and 0.60 are presented. A valve whose area ratios equal 0.50 is a usual poppet valve. According to area ratios, the proportional poppet valve has different static characteristics. Many calculations of static characteristics of proportional poppet valves of various area ratios were carried out. From these results, area ratios were determined to be 0.55 for the proportional poppet valve used in experiments. Experimental results and calculated results of static characteristics of a compensated valve $\left(S_{r}=S_{s}=0.55\right)$ are presented in Fig.7. Symbols used in Fig. 7 are explained in Table 1. Comparing with static characteristics of an uncompensated valve presented in Fig.3, static characteristics presented in Fig. 7 is much more favorable for a flow control valve. In Fig.8, experimental results of lift $x$ of this compensated valve are presented. Symbols used in Fig. 8 are also explained in Table 1 . When the load pressure increases, the main poppet lift also increases. Therefore the decrement in oil flow rate can be compensated by the increment in the poppet 1ift. In Fig.7 and Fig.8, calculated results showed a good agreement with experimental results. From these results, it has become clear that the area compensation method is effective and that static characteristics of a proportional poppet valve designed by the area compensation method are accuaretly predicted by calculations.

As an example of prediction of static characteristics, calculated results of static characteristics for two supply pressures and for two poppets of diameter of a proportional poppet valve designed by the area compensation method are presented in Fig.9 and Fig.10. Calculations were performed for several pilot valve opening

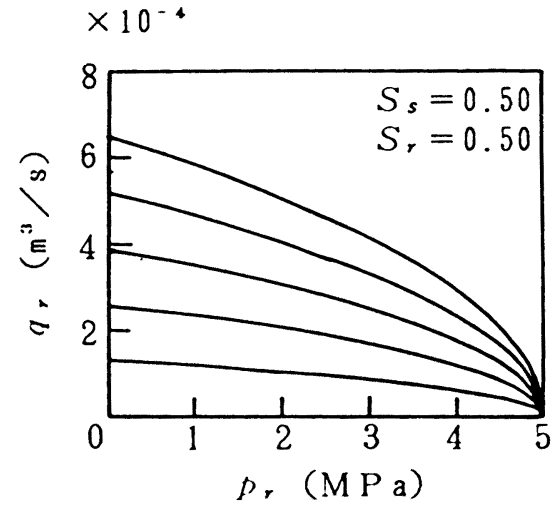

(a)

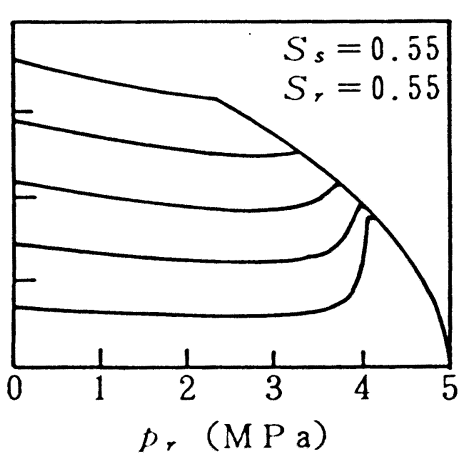

(b)

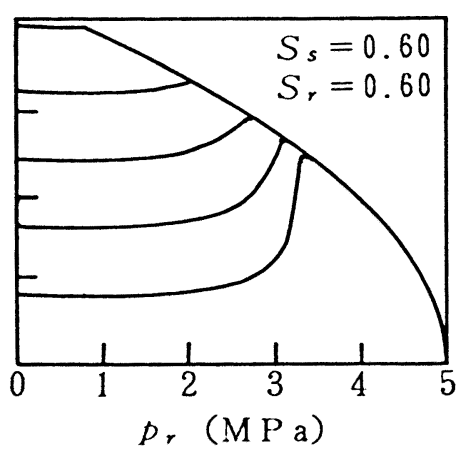

(c)

Fig. 6 Computed results of static characteristics of proportional poppet valves of various area ratios

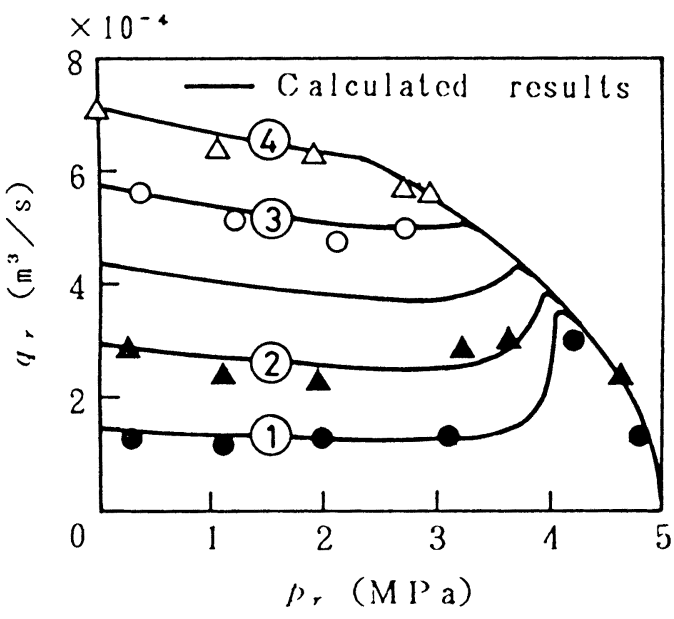

Fig.7 Experimental results of static characteristics of a proportional poppet valve designed by area compensation method

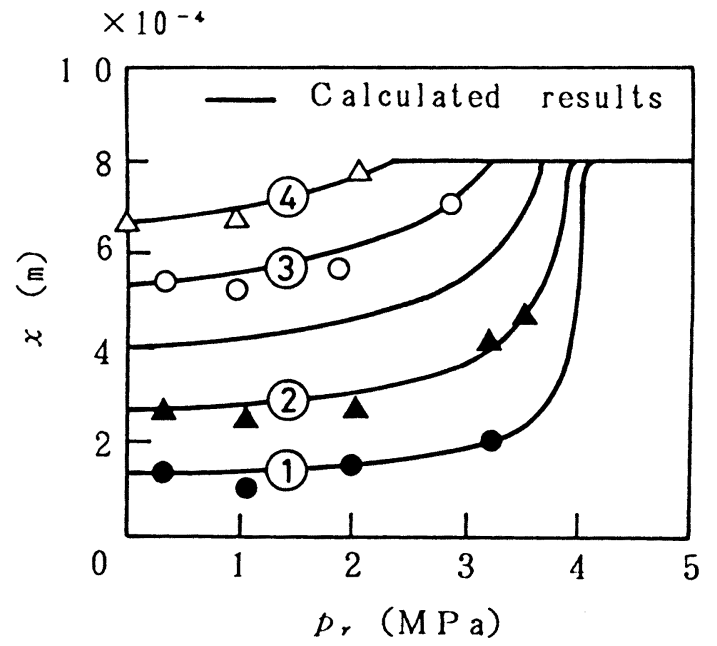

Fig.8 Experimental results of poppet lift of a proportional poppet valve designed by area compensation method 
374

areas $f_{y}$. Calculated results for two supply pressures $\left(p_{s}=5\right.$ and $\left.20 \mathrm{MPa}\right)$ are presented in Fig.9. As supply pressure $p_{s}$ becomes larger, static characteristics are more compensated. And calculated results for two poppets of diameter $(I)=16$ and 20 $\mathrm{mm})$ are presented in Fig.10. As poppet diameter becomes larger, the controllable range of flow rate extends more widely.

\section{CONCLUSION}

In this report, the area compensation method of a proportional poppet valve has been investigated. From detailed experiments and considerations, the following has become clear.

(1) Static characteristics of an uncompensated poppet valve are considerably influenced by load pressure.

(2) A usual compensation method using a pressure-compensated flow control valve as a pilot valve is effective, but the

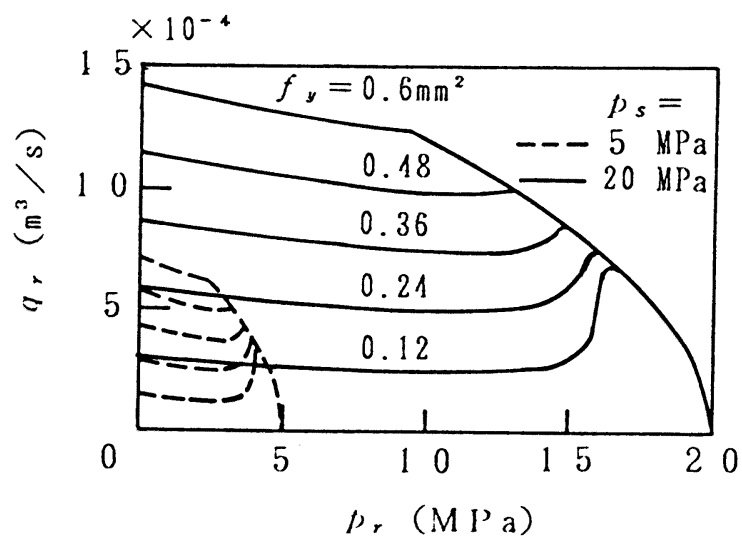

Fig.9 Static characteristics of proportional poppet valves with supply pressures of 5 and $20 \mathrm{MPa} \quad\left(S_{s}=S_{r}=0.55\right)$

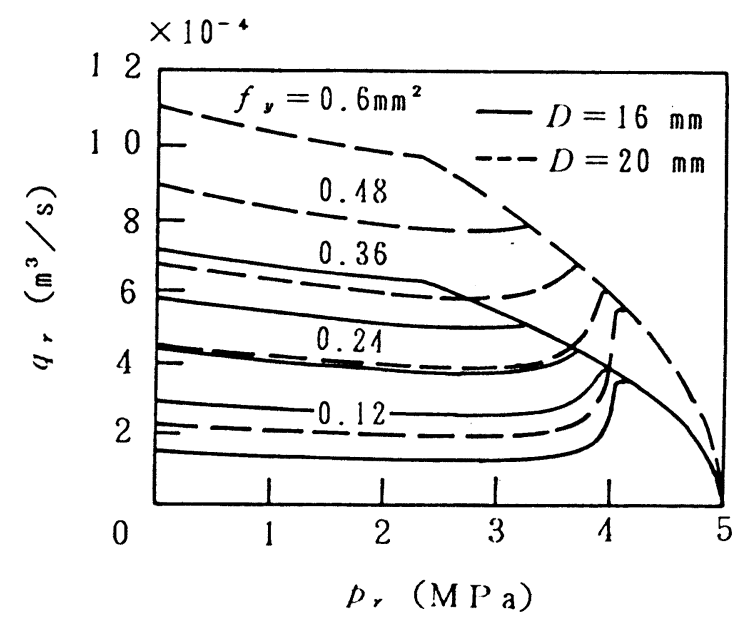

Fig. 10 Static characteristics of proportional poppet valves of 16 and $20 \mathrm{~mm}$ in diameter of a main poppet $\left(S_{s}=S_{r}=0.55\right)$ valve structure may become considerably complicated.

(3) The area compensation method is a very effective method.

(4) The structure of a proportional poppet valve designed by the area compensation method is simple.

(5) Static characteristics of a proportional poppet valve compensated by the area compensation method can be accurately calculated.

\section{REFERENCES}

(1) B.Andersson, Entwicklung eines Lastdruck Kompensierten Load Sensing Wegeventiles mitstetig wirkenden 2-WegeEinbauventilen, Preprint AFK, 6, (1984), 255.

(2) P. WU and A. KITAGAWA, A study on the Poppet Valve with Series Restriction Chokes (lst Report, The Mathematical Analysis and Experiments of Static Characteristics), Trans. Jpn. Soc. Mech. Eng., Vol.53, No.490, (1987), 1750.

(3) P. WU, A. KITAGAWA and T. TAKENAKA, A Study on the Poppet Valve with Series Restriction Chokes (2nd Report, The Mathematical Analysis and Experiments of Dynamic Characteristics on a Directional /Flow Control), Trans. Jpn. Soc. Mech. Eng., Vol.53, No.493, (1987), 2824.

(4) P. WU, A. KITAGAkA and T. TAKENAKA, A Study on the Poppet Valve with Series Restriction Chokes (3rd Report, Proposition of New Type Logic Valve and Static Characteristics of Newly Proposed Relief Logic Valve), Trans. Jpn. Soc. Mech. Eng., Vol.54., No.498., (1988), 404.

(5) B.Andersson, on the Valvistor : A Proportionally Controlled Seat Valve, Linkoping Studies in Science and Technology, Dissertation, No. 108. 